\title{
The History of the Papuan and Australian Languages
}

Almost a thousand languages spoken in the Pacific region do not belong to the Austronesian family. Of these, more than seven hundred are spoken in or near New Guinea and are known by the general term "Papuan"; the remaining two hundred or so are, or were, spoken in Australia. We know much less about the history of these languages than about the history of the Austronesian languages.

The majority of Papuan languages are located in the interior of the island of New Guinea. This area experienced no European contact until shortly before (and even in some cases some time after) World War II. So while many of the languages east of New Guinea had been written for a hundred years or more, and had been studied in some detail, most Papuan languages were unknown to the outside world until very recently.

Missionary linguists (especially those working with the Summer Institute of Linguistics) were largely responsible for dramatically increasing our knowledge of Papuan languages in the decades after 1945, and the picture is considerably clearer than it was in, say, the 1960s. Nevertheless, there are still very many Papuan languages about which almost nothing is known, and the work of comparative linguistics has barely begun. Where Australia is concerned, the death of many languages before they had been properly recorded leaves us with gaps of a different Kind. Much of the evidence needed to make historical inferences has disappeared, and formulating and testing historical hypotheses is hampered at every turn.

As if these problems were not enough, we are faced with a much longer period of human habitation in both Australia and New Guinea than in most of the rest of the Austronesian-speaking world. The longer a group of languages have had to diversify, the fewer will be their apparent similarities. 
In dealing with the history of both Papuan and Australian languages, I can make only general and tentative statements.

\subsection{Interrelationships of Papuan Languages}

\subsubsection{Papuan Language Families}

The term Papuan refers to those languages of the Pacific region, excluding Australia, that are not members of the Austronesian language family. It does not refer to a single family of languages: "Papuan languages are not all genetically related. They do not all trace their origins back to a single ancestral language. On the basis of present knowledge, they belong to at least sixty different language families, all with their own common ancestral language" (Foley 1986, 3; emphasis mine). Some linguists prefer the label "Non-Austronesian" for these languages, since it does not imply the genetic unity that a positive label like "Papuan" does. "Non-Austronesian," however, like any negative label, has its own problems-Russian, Chinese, English, and Swahili, after all. are also nonAustronesian languages-so I use the term "Papuan" in this book.

While Foley does not explicitly define the criteria he uses in deciding membership or nonmembership of a family, it is clear from his conclusions that relatively close relationship is involved. As far as these sixty or so families are concerned, their "wider relations [are] not yet conclusively demonstrated. Undoubtedly, with more careful and complete comparative work, this picture will become simpler; a number of families will probably combine into larger families, as Romance, Germanic and Slavic combine into the Indo-European family" (Foley 1986, 3).

In this initial discussion of Papuan language families, I follow Foley's conservative view; later I discuss proposed combinations of these families. The list of Papuan families in table 4 proceeds generally on a west-to-east basis, with the number for each family corresponding to that on map 15 . The locations given in table 4 refer to geographical regions in Irian Jaya and to province names in Papua New Guinea.

The situation is, however, even more complicated than table 4 indicates. Not every Papuan language belongs in a (smaller or larger) family. A number of Papuan languages are currently classified as isolates. The term isolate refers to a one-member family, a language that, on the basis of current evidence, appears to have no relatives.

\subsubsection{Possible Wider Groupings of Papuan Families}

Naturally enough, the existence of so many language families in such a relatively small geographical area has caused many linguists to look for wider 
Table 4. Papuan Language Families

Family

Location $^{\mathbf{a}}$

Number of

languages

\section{West of the New Guinea mainlan.}

1 Timor-Alor-Pantar Timor area

2 Northern Halmahera Halmahera Islands

18

11

\section{Mainland Irian Jaya only ${ }^{\mathbf{b}}$}

3 West Bird's Head

Bird's Head

6

4 Central Bird's Head

5 Borai-Hattam

Bird's Head

4

Bird's Head

6 South Bird's Head

Bird's Head

10

Bird's Head

western

4

Merah

9 West Bomberai

western

3

10 East Cenderwasih

western

Bay

11 Tor-Lake Plain

northern

20

12 Nimboran

northeast

northeast

northeast

4

northeast

central

11

central

eastern

southeast

southeast

Frederick Hendrik

Both sides of the Irian Jaya-Papua New Guinea border ${ }^{c}$

22 Sko

23 Border

24 Kwomtari

25 Senagi

26 Central-South New Guinea

27 Marind

28 Trans-Fly north coast

northern

12

northern

northern

central

54

southern

south coast 


\section{Mainland Papua New Guinea only}

29 Torricelli

$30 \quad$ Upper Sepik

31 Ram

32 Tama

33 Yellow River

34 Middle Sepik

35 Sepik Hills

36 Leonhard Schulze

$37 \quad$ Nor-Pondo

38 Yuat

39 Mongol-Langam

40 Waibuk

41 Arafundi

42 Keram (Grass)

43 Ruboni

44 Goam

45 Annaberg

46 Arai

47 Amto-Musian

48 Mugil-Isumrud-Pihom

49 Josephstaal-Wanang

50 Brahman

51 Mabuso

52 Rai Coast

53 East New Guinea Highlands

54 Finisterre-Huon

55 Gogodala-Suki

56 Kutubuan

57 Turama-Kikorian

58 Teberan-Pawaian

59 Inland Gulf

60 Eleman

61 Angan

62 Binanderean

63 Central-Southeast New Guinea
East \& West Sepik,

Madang

East Sepik

16

West Sepik

East and West Sepik

West Sepik

East Sepik

12

East Sepik

East Sepik and West-

ern

East Sepik

East Sepik

East Sepik

Enga, Madang

East Sepik

East Sepik, Madang

East Sepik, Madang

Madang

Madang

East Sepik

West Sepik

Madang

Madang

12

Madang

Madang

Madang

29

all Highlands

42

provinces

Morobe

65

Western

3

Southern Highlands 5

Gulf

Simbu, Gulf 3

Gulf

Gulf

Gulf

Oro

Central, Milne Bay

36 


\section{East of the New Guinea mainland}

64 New Britain

65 South Bougainville

66 North Bougainville

67 Yele-Solomons
East New Britain,

New Ireland

Bougainville

Bougainville

Milne Bay, Solomon

Islands

\section{8}

Solomon Islands

${ }^{\mathrm{a}}$ Geographical designations in Irian Jaya; province names in Papua New Guinea.

${ }^{\mathrm{b}}$ There are a number of isolates in addition to the languages listed here.

${ }^{\mathrm{C}}$ The isolate Yuri belongs in this group.

${ }^{\mathrm{d}}$ Several isolates occur in this group.

relationships between them. If the neighboring Austronesian languages can apparently be classified into a single large family, then can we not at least reduce the number of Papuan language families? Scholars at the Australian National University, particularly S. A. Wurm, have attempted to establish larger groupings of Papuan languages on the basis of what seem to be shared features. Lack of adequate information about many languages has hampered this work. While some of the proposals rest on solid data, others are much more impressionistic. Map 16 shows the locations of proposed wider groupings.

Wurm borrowed terms from the biological sciences to refer to some of these wider groupings of languages. A stock is a group of language families that appear to be reasonably closely related to each other, while a phylum is a group of distantly related families or stocks. In table 4, I have often treated as families groups that other linguists refer to as stocks. The degree of relationship between Papuan languages of the same stock roughly parallels that between geographically dispersed members of the Austronesian family, but the concept of a phylum is quite different, as it implies only a very distant relationship. The techniques and procedures of comparative linguistics have not yet been able to prove the existence of such attenuated relationships.

One proposed phylum is the West Papuan phylum, consisting of the Northern Halmahera, West Bird's Head, Central Bird's Head, and Borai-Hattam families (families 2 through 5 in table 4) along with the Amberbaken isolate, for a total of twenty-four languages, all in the extreme west of Irian Jaya. These languages have in common a certain amount of lexical similarity 


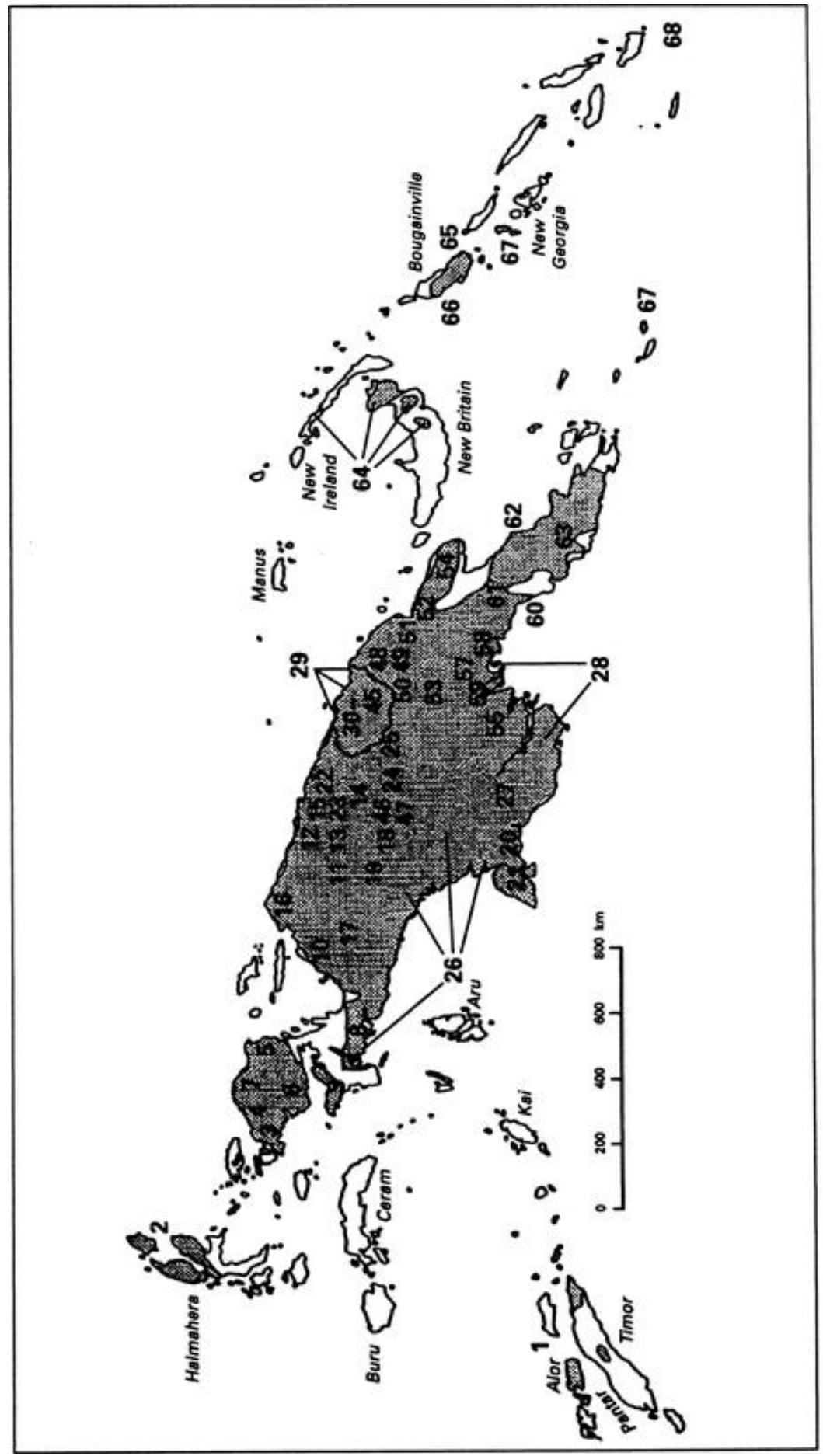

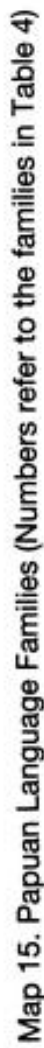




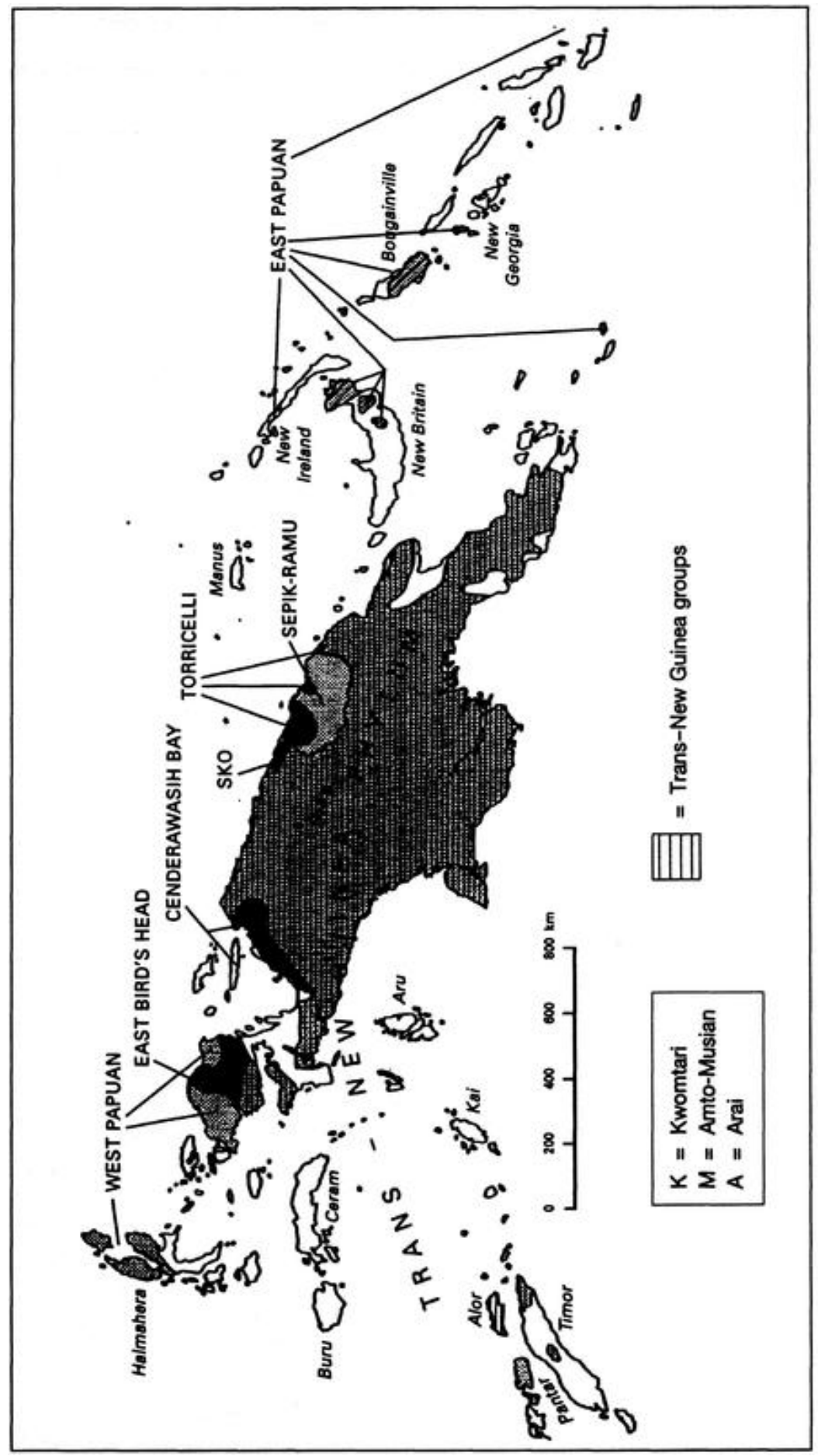

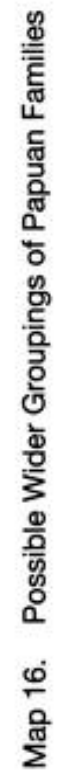


and some grammatical features (e.g., the marking of subject and object by verbal prefixes rather than suffixes [Wurm 1982, 208]).

Another suggested wider grouping is the Sepik-Ramu phylum, consisting of more than one hundred languages belonging to sixteen different families (numbered 30 through 45 in table 4) and spoken mainly in the East Sepik, West Sepik, and Madang provinces of Papua New Guinea. (A few nearby isolates would also be members of this phylum.) These languages share a number of distinct phonological features, such as a very small number of vowel phonemes, and also have some common grammatical features (Wurm 1982, 210).

The Torricelli family (29 in table 4 ) is treated by Wurm as the Torricelli phylum, composed of perhaps five or six families. Foley (1986, 241-242), however, treats this as a single family, largely because these languages share a number of grammatical features not found elsewhere among Papuan languages. (Subject prefixes and complex noun-class systems are two examples.)

Wurm has also grouped the Papuan languages spoken east of the New Guinea mainland into the East Papuan phylum. This consists of twentyfive languages belonging to the New Britain, South Bougainville, North Bougainville. Yele-Solomons, and Reefs-Santa Cruz families (64 through 68 in table 4). There appears to be some lexical and grammatical evidence for the existence of this group, though it is not very strong, and the situation is complicated by the heavy Austronesian-language influence on some of the members of the phylum.

The largest and possibly most controversial genetic grouping Wurm proposes is the Trans-New Guinea phylum. This hypothesis, in its most extreme form, proposes that almost all the rest of the Papuan languages-with the exceptions of a few small families and some isolates-belong to a single genetic group of about five hundred languages stretching from Timor in the west to Milne Bay in the east. It would include all of the languages of the southern and central part of the mainland, as well as some spoken in the north $(1,6,8,9,11-21,23,25-27$, and 48-63 in table 4). There are certain phonological and grammatical features shared by at least some members of this group, but the existence of the phylum as a whole-at least at this stage of our research-seems tenuous, to say the least. Some support for the hypothesis can be found in Pawley (1995).

A number of the families listed in table 4 cannot at present be assigned to any phylum even under the most liberal application of the comparative method. These lone families are the East Bird's Head. Cenderawasih Bay (plus the isolate Yava). Sko, Kwomtari, Arai, and Amto-Musian families (see map 16). 


\subsection{Interrelationships of Australian Languages}

\subsubsection{Mainland Australia}

Some linguists have divided the languages of mainland Australia into two pseudogenetic groups. The Pama-Nyungan group of languages occupies about three-quarters of the mainland. Its name comes from the words meaning 'man' at the northeastern and southwestern extremes of the group (Dixon 1980, 221). These languages are very similar typologically in both phonology and grammar. The remaining languages-referred to by the negative term Non-Pama-Nyungan-occupy the northwest of the mainland (see map 11 in chapter 2). They are phonologically fairly similar to the PamaNyungan languages, but grammatically quite different.

In the 1960s a lexicostatistical classification of the Australian languages divided the languages into twenty-six "phylic families" (those sharing 15 percent basic vocabulary or less). Of these groups, one was Pama-Nyungan, and each of the remaining twenty-five-Non-Pama-Nyungan-groups was held to be a "phylic family" on a par with Pama-Nyungan (Dixon 1980, 263).

Dixon himself is highly distrustful of this classification. A majority of linguists now agrees that all the mainland languages belong to a single, Australian, family. The differences between Pama-Nyungan and Non-PamaNyungan languages are developmental rather than original: "It seems clear ... that nearly all the languages of Australia form one genetic family, going back to a single ancestral language, proto Australian" (Dixon 1980, 228). Because of the thousands of years of contact between Australian languages, however, shared innovations supporting subgrouping hypotheses are extremely hard to find: "Present knowledge of the relationships between Australian languages is not sufficient to justify any sort of fully articulated 'family tree' model.... It could perhaps be that the continual levelling due to diffusion of features of every sort has obscured those genetic splits that did take place in the development of Australian languages, so that it will not be possible to reconstruct them" (Dixon 1980, 264-265).

\subsubsection{Tasmania}

Genocide in Tasmania has led to the loss of all Tasmanian languages. An Aboriginal population of possibly five thousand people at the time of first European contact, speaking somewhere between eight and twelve languages, was exterminated in less than eighty years. The last full-blooded Tasmanian died in 1888, although there are still about four thousand people of partial Tasmanian Aboriginal descent living in Tasmania and elsewhere. So little was recorded of these languages that it is almost impossible to say anything 
about them (Crowley 1993). As regards their history, Dixon $(1980,233)$ says, "All we can conclude is this-there is No evidence that the Tasmanian languages were NOT of the regular Australian type. They have been separated off for so long, and the available materials are so poor, that the likelihood of a genetic connection cannot be confirmed. The genetic affiliation of Tasmanian is, and must remain, unproven."

\subsection{Possible External Links}

Suggestions about the wider relationships of Papuan and Australian languages have not been lacking, but given the long periods of time involved, most of these can remain no more than suggestions. Greenberg's (1971) Indo-Pacific Hypothesis attempts to link Papuan languages with those of Tasmania (but not mainland Australia) and of the Andaman Islands in the Indian Ocean. Greenberg speculated that Australian languages are related to the Dravidian languages of South India. Scholars and amateurs have also looked for relationships between Papuan or Australian languages and those of Africa and Asia. None of these hypotheses seems to be based on any evidence more solid than typological similarities or a few possibly accidental lexical similarities.

Foley (1986, 271-275), however, has recently presented a small but tantalizing amount of evidence for the existence of a genetic link between Australian languages and the languages of the Eastern Highlands of Papua New Guinea. A small number of basic vocabulary items look as if they might be cognate. But he says that this evidence "in no way constitutes proof of a genetic relationship between Australian and Eastern Highlands languages.... Much more detailed and careful research needs to be done before a convincing proof is provided, and. given the time depth, that may never be possible. Rather, the above data represent a first attempt at marshalling some evidence for a genetic link between Australian and Papuan languages” (Foley 1986, 275).

Up until around eight thousand years ago. New Guinea and Australia were one continent. Only then did sea levels start rising after the last Ice Age to form what is now the Torres Strait. It is distinctly possible that Australia was settled from the New Guinea area, so the idea of a genetic link between the two areas cannot be ruled out.

\subsection{Implications for Prehistory}

\subsubsection{Origins}

The New Guinea mainland was probably occupied at least fifty thousand years ago, presumably by the ancestors of the speakers of (some) Papuan 
languages; Australia was also settled at about the same time. Since comparative linguistics cannot reach back more than about eight or ten thousand years, most of that fifty-thousand-year period is lost to linguistics.

It is possible that all the Papuan families are related, descending from a single "Proto Papuan" ancestor that we cannot even dimly imagine. A single language, spoken somewhere in the New Guinea area around 50,000 B.C., could have given rise, over time, to all of the modern Papuan languages, and this language may have been the ancestral language from which all Australian languages ultimately derive.

We also have no evidence to indicate the origins of the first speakers of Papuan or Australian languages. Linguistic connections with Asia or Africa are nothing more than highly speculative, nor would we expect otherwise. If the time elapsed is too great to show interrelationships among all Papuan languages, it is certainly too great to show genetic relationships between these languages and those to the north, south, or west.

But perhaps this very lack of evidence for external relatives means that the Papuan languages do, or did, form a genetic unity, and that the same could be said about the Australian languages. If the diversity existing among modern Papuan and Australian families is due to different origins and different migrations of people at various times from various locations, one might expect to find some genetic connections between individual Papuan or Australian families and Asian or African language families. The fact that we do not, while not strong enough to be called evidence, does suggest that the Papuan languages may have formed a single linguistic grouping in the very distant past, and that the same may be true of Australian, Tasmanian included.

In only a few instances has there been anything in the way of comprehensive reconstruction of the phonology, grammar, and vocabulary of any of the larger Papuan families, and the situation in Australia is pretty similar. Little can be said about relations with other families, origins and migration routes, and earlier stages of Papuan or Australian culture, and the little that has been said on these topics must be treated as highly speculative.

\subsubsection{Diversification}

One question that must be asked in any study of the Papuan and Australian situations is, if both New Guinea and Australia have been settled for about the same length of time, why do we find such incredible genetic diversity among Papuan languages, whereas Australian languages all seem to belong to just a single family?

Physical geography, and its effect on wide-ranging human movement, is one contributing factor: "Most of New Guinea is difficult country indeed, 
steep, forest-covered mountains with precipitous drops, swirling rivers, dense, nearly impenetrable rainforests and endless tracts of swampland. The terrain thus poses some genuine barriers to human social interaction and would certainly favour, rather than inhibit, linguistic diversity" (Foley 1986, 9). Geographical barriers like these were often bolstered by social barriers. Hostile relations were the rule between neighboring communities, and the tendency of language to take on emblematic functions and to be considered as a mark of group identity throughout Melanesia is one sign of communities' desires to set themselves apart. People often created linguistic differences, or exaggerated differences that already existed, in order to preserve their group membership.

Kulick (1992, 2-3), for example, quotes the following observation made by Ken McElhanon, who worked among Selepet speakers in Papua New Guinea: "The people living in the Selepet-speaking village of Indu had gathered together for a meeting. During this meeting, a decision was reached to 'be different' from other Selepet speakers. It was agreed that the villagers of Indu would immediately stop using their usual word for 'no,' bia, which was shared by all their fellow speakers of Selepet. Instead, they would begin saying buyc, which they did and have continued doing since that time." There are many other similar examples. In Buin (spoken in Bougainville), speakers of the Usai dialect have reversed all gender agreements: masculine markers in other dialects become feminine in Usai, and feminine markers become masculine (Laycock 1982a). Similar phenomena can be observed in Oceanic languages. Speakers of Ririo (Choiseul. Solomon Islands) seem to have deliberately transposed the last consonant and vowel of words to make them sound more different from their counterparts in the neighboring closely related language of Babatana (Laycock 1982b, 274-276):

\begin{tabular}{|c|c|c|}
\hline Babatana & Ririo & \\
\hline sosole & susuel & 'naked' \\
\hline vumi & vuim & 'beard' \\
\hline piru & piur & 'wild' \\
\hline bose & bues & 'man' \\
\hline
\end{tabular}

The Australian continent is in some ways less difficult geographically than New Guinea, and physical barriers to long-distance communication are generally much less extreme. Though Australians belonged to distinct tribal and linguistic groups, there was much more social interaction between those groups, typically accompanied by transfer of vocabulary items from one group to another. Rather that accentuating differences, Australians seem to have made an active effort to keep different languages from becoming too different. Dixon $(1980,239)$ refers to "a gradual but constant 
shifting of tribal groups," through which people came into contact with different languages. He also mentions mergers of different tribal groups whose numbers had been reduced by famine or disease. Such factors conspired to keep Australian languages more similar to each other than one might expect, especially in comparison to Papuan languages.

Both Papuan and Australian languages have been in the Pacific region for a very long time indeed. We know nothing of where they came from and little of how their speakers moved around the region. We do not know how far east or west of the New Guinea mainland Papuan speakers might have originally settled or much about their connections with Australian languages. All we can reasonably deduce is that, by the time speakers of Austronesian languages arrived in this area about four to five thousand years ago or so, speakers of Papuan and Australian languages were very much entrenched. 